\title{
ESBL-producing Klebsiella sp. isolated from raw milk of healthy cow in small holder dairy
} farms of Mymensingh district in Bangladesh

\author{
A. Nahar, A. K. M. A. Islam ${ }^{1}$, M. N. Islam ${ }^{1}$, M. M. Alam* \\ Department of Medicine, Faculty of Veterinary Science, Bangladesh Agricultural University, \\ Mymensingh-2202, Bangladesh \\ ${ }^{1}$ Department of livestock services, Government of the People's Republic of Bangladesh, Farmgate, \\ Dhaka
}

\begin{abstract}
Background: The emergence of extended-spectrum beta-lactamase (ESBL) bacteria such as Klebsiella sp. in milk is a serious public health concern. Antibiotic resistance profile and molecular characterization of ESBL-producing Klebsiella sp. (ESBL-Kleb) from milk of healthy cow have not yet been reported in Bangladesh. This study aims to detect and characterize ESBL-Kleb from milk samples of the healthy cow in the smallholder dairy farm of Mymensingh district, Bangladesh.

Methods: A total of 100 milk samples were collected from apparently healthy cows of smallholder dairy farms. Klebsiella $\mathrm{sp}$. was isolated from milk samples as per standard methods. The detection of ESBL-Kleb was done phenotypically by a double-disc synergy test. Subsequently, ESBL gene grouping of the isolates was done by multiplex PCR. Antimicrobial susceptibility testing of the ESBLKleb isolates was done using the common 15 antimicrobials by the disc diffusion method.

Results: In this study, Klebsiella sp. was isolated from $30(30 \%)$ samples whereas $20(67 \%)$ of the isolate was ESBL producer both phenotypically and genotypically with the presence of ${ }^{b l a}$ TEM and ${ }^{b l a}$ SHV individually or combined ( ${ }^{b l a}$ TEM plus ${ }^{b l a}$ SHV). The ESBL-positive isolates were highly resistant against commonly used antibiotics such as ampicillin, cefotaxime, gentamicin $(100 \%)$, ceftazidime $(80 \%)$, cotrimoxazole/trimethoprim $(40 \%)$, and oxytetracycline $(30 \%)$. Most importantly multidrug resistance (MDR) was found in a high number of the ESBL-Kleb isolates. However, the isolates were $100 \%$ sensitive to drugs such as ceftriaxone, imipenem, azithromycin, chloramphenicol, and cefepime. To the best of our knowledge, this is the first report of detection of ESBL-Kleb in raw milk of healthy cow of smallholder dairy farm in Bangladesh.

Conclusion: The presence of a high number of MDR ESBL-Kleb in raw milk of healthy cows of smallholder dairy farms might be alarming for public health.

Keywords: Drug-resistant, PCR, Ampicillin, Cefotaxime, Gentamicin, ceftazidime, oxytetracycline
\end{abstract}

*Correspondence: email:asamahbub2003@yahoo.com

All right reserved 0475/2021

Copyright (C) 2021 Bangladesh Society for Veterinary Medicine. This is an open access article under the CC BY license (http://creativecommons.org/licenses/by/4.0/), which permits unrestricted use, distribution, and reproduction in any medium, provided the original author and source are credited. 


\section{Nahar and others}

\section{Introduction}

Klebsiella sp. is an important opportunistic pathogen that causes a variety of infectious diseases in humans, including septicemia, liver abscesses, diarrhea, and pneumonia (Guo et al., 2017). It is a well-known hospital-acquired pathogen and associated with increased patient morbidity and mortality (Cabral et al., 2012). In addition to the clinical environment, Klebsiella $\mathrm{sp}$. is frequently reported in foodborne outbreaks and has been considered as an important foodborne pathogen (Davis and Price, 2016). In recent years, an increasing number of food-borne outbreaks caused by Klebsiella sp. have been reported in different countries (Zhou et al., 2011; $\mathrm{Yu}$ and Zhou, 2013). The incidence of infections due to Klebsiella sp. resistant to beta-lactam agents has increased sharply in recent years (Lautenbach et al., 2001).

Extended spectrum beta-lactamases (ESBL) can hydrolyse penicillins, first, second and thirdgeneration cephalosporins, and aztreonam (but not cephamycins or carbapenems). The most prevalent ESBLs are TEM, SHV, and CTX-M variants (Tekiner et al., 2016). After 2000s, CTX-M type enzymes have exhibited dominancy over TEM and SHV type enzymes in wide range of areas (Woerther et al., 2013). The CTX-M variants are also clustered in five major groups: 1, 2, 8, 9, and 25 (Bonnet, 2004). Resistance to beta-lactam antibiotics is most commonly found in Klebsiella pneumoniae (Alipourfard and Nili, 2010, Badri et al., 2017). ESBL-encoding genes have been frequently found on plasmids, which can also carry other antimicrobial resistant (AMR) genes related to aminoglycosides, chloramphenicol, sulfonamide, tetracycline, macrolides, etc. (Naseer et al., 2011; Phuc Nguyen, 2009). Antimicrobial such as penicillin, tetracycline, sulphonamides, aminoglycosides are commonly used as therapeutics in dairy animal of Bangladesh (Rahman et al., 2017).

In general, milk is highly nutritious and complete food both for adult and young children. However, milk may get rapidly spoiled by bacteria due to improper handling and storage of milk and poor management of the animal (Oliver et al., 2005).Bacteria under Enterbacteriaceae causing infection through milk which has a great effect on human health (Hickey et al., 2015). The prevalence of ESBL-Kleb in food producing animal, animal products, and hospital settings is increasing in the globe including Bangladesh (Alipourfard and Nili, 2010, Gundogan and Avci, 2013, Badri et al., 2017). These pathogens pose a major challenge for the treatment of infections caused by them and cause a problem with the extensive use of second-or third-generation antibiotics for the treatment of bacterial infections (Tenover et al., 2009). ESBL-Kleb is mostly insensitive to lots of commonly used antibiotics causing an increase in the use of last-resort antimicrobial drugs (i.e., carbapenems) during treatment. Hence, the presence of ESBL-Kleb in the food processing chain or in the food of our daily consumption which is possibly coming from healthy farm animals is the fact which has to be appropriately investigated.

Smallholder farming system (herd size $<4$ cattle per household) contributes greatly in our national economy. This farming is commonly practiced by low income people in many areas of Bangladesh including Mymensingh. However, farmers of small holder dairy farm are not aware of judicial use of antimicrobials. Hence, they frequently use antimicrobials irrationally as therapeutics or prophylaxis for the dairy cattle. Until now, most investigations on AMR pattern of bacteria focused mainly on E. coli, Salmonella sp., Campylobacter sp.from food samples in Bangladesh. In contrast, little information was obtained on AMR of Klebsiella sp. isolated from food samples. Most importantly, AMR profile and molecular characteristics of ESBL-producing Klebsiella sp. from milk of healthy cow have not yet been reported in Bangladesh.

Therefore, this study was conducted to detect ESBL-Kleb from raw milk of healthy cow in small holder dairy farm of Mymensigh district, Bangladesh. 


\section{Materials and methods Sample collection}

A total of 100 raw milk samples were collected from small holder dairy farms of 4 upazilas of Mymensingh district including Mymensingh Sadar, Muktagaccha, Fupur and Tarakanda between September 2020 and June 2021. Approximately $15 \mathrm{ml}$ of milk samples were collected in sterile plastic containers directly from the teats of the cows and were transported to the laboratory in the Department of Medicine, Faculty of Veterinary Science, Bangladesh Agricultural University for further study. All cows were apparently healthy and did not show any clinical signs of mastitis. Prior to milk sample collection, udder including teats was disinfected with $70 \%$ alcohol.

\section{Isolation and identification of Klebsiella sp.}

Raw milk samples were enriched according to protocol described by Ombarak et al. (2016) with slight modification. One $\mathrm{ml}$ of milk samples were enriched in $9 \mathrm{ml}$ of sterile nutrient broth at $37^{\circ} \mathrm{C}$ for $16 \mathrm{~h}$ with static condition. Subsequently, a loopful of enriched culture was streaked onto MacConkey agar (HiMedia, India) containing 1 $\mathrm{mg} / \mathrm{ml}$ cefotaxime (CTX) (Nihon Becton Dickinson, Japan) according to a protocol described earlier (Nahar et al., 2018). Two pink mucoid colonies for each sample were further streaked in slant for biochemical assays of the isolated Klebsiella sp. following the prescribed biochemical tests according to methods described earlier (Salauddin et al., 2019).

\section{ESBL phenotyping}

The isolates were screened for ESBL production by double-disc synergy test using CTX and ceftazidime (CAZ) with or without clavulanic acid (CA) as recommended by the Clinical and Laboratory Standards Institute (CLSI, 2014). The isolate was considered as ESBL-producer when there was $5 \mathrm{~mm}$ or greater increase in the zone of inhibition with CTX or CAZ disk with CA in comparison to CTX or CAZ alone.

\section{ESBL gene grouping}

Genomic DNA of the isolates was extracted by boiling of $1 \mathrm{ml}$ of overnight culture according to method described previously (Parvin et al., 2021). ESBL gene grouping ( ${ }^{b l a} \mathrm{TEM},{ }^{b l a} \mathrm{SHV}$, ${ }^{b l a}$ CTX-M-1, and ${ }^{b l a}$ CTX-M-2) was carried out by multiplex polymerase chain reaction (PCR) using primer set and PCR condition described earlier (Parvin et al., 2021). In brief, amplification reactions were set in a $25-\mu 1$ volume containing $12.5 \mu \mathrm{l}$ of PCR master Mix (New England Biolabs, UK), $1.0 \mu \mathrm{l}(10 \mathrm{pmol})$ of each of the forward and reverse primers, $1 \mu \mathrm{l}$ of DNA, and $3.5 \mu 1$ of nuclease-free water. PCR was run using T100 thermal cycler (Bio-Rad laboratories, Inc.) with multiplex PCR conditions as follows: initial denaturation at $95{ }^{\circ} \mathrm{C}$ for $5 \mathrm{~min}$, followed by 25 cycles of denaturation at $95{ }^{\circ} \mathrm{C}$ for $30 \mathrm{~s}$, annealing at $60^{\circ} \mathrm{C}$ for $1 \mathrm{~min}$, and extension at 72 ${ }^{\circ} \mathrm{C}$ for $1 \mathrm{~min}$, with a final extension at $72{ }^{\circ} \mathrm{C}$ for 10 min. Appropriate positive and negative controls (sterile phosphate buffer saline) were included in each PCR run. The PCR products were visualized by electrophoresis on a $1.5 \%$ agarose (TaKaRa, Japan) gel containing ethidium bromide. The DNA bands were photographed using a UV transilluminator (Cell biosciences, Australia).

\section{Determination of antimicrobial susceptibility}

ESBL-Kleb isolates were tested for antimicrobial susceptibility by the disk diffusion method (CLSI, 2012) using commercially available discs (Nihon Becton Dickinson, Japan; Biomaxima, Lublin, Lubelskie; Poland, Himedia, India) against 15 antimicrobials belonging to 10 antimicrobial classes. The antimicrobial classes were considered according to CLSI guidelines (CLSI, 2012). They included penicillins [ampicillin (AMP, $10 \mu \mathrm{g})$ ], cephems [(CTX, 30 $\mu \mathrm{g})$, CAZ $(30 \mu \mathrm{g})$, cefoxitin (FOX, $30 \mu \mathrm{g}$ ), ceftriaxone (CRO, $30 \mu \mathrm{g})]$, cefepime (FEP,30 $\mu \mathrm{g})$ ], carbapenem [imipenem (IPM,10 $\mu \mathrm{g})$ ], aminoglycosides [gentamicin (GEN, $10 \mu \mathrm{g}$ ), streptomycin (STR, $300 \mu \mathrm{g})]$, quinolone [nalidixic acid (NAL, $30 \mu \mathrm{g}$ )], fluoroquinolone 


\section{Nahar and others}

[ciprofloxacin (CIP, $5 \mu \mathrm{g})$ ], tetracycline [oxytetracycline (OTC, $30 \mu \mathrm{g})$ ], phenicol [chloramphenicol (CHL, $30 \mu \mathrm{g})$ ], macrolide [azithromycin (AZM, $15 \mu \mathrm{g})$ ], and sulphonamides/dihydrofolatereductase

[cotrimoxazole-trimethoprim (SMZ/TMP, 25 $\mu \mathrm{g})]$. Inbrief, ESBL-Kleb kept as glycerol stock at $-80^{\circ} \mathrm{C}$ were sub-cultured on nutrient agar and 3 to 5 Klebsiella sp. colonies were collected and suspended in $5 \mathrm{ml}$ of sterilized saline. The suspension was adjusted to achieve turbidity equivalent to $0.5 \mathrm{McF}$ arland standards. By using sterile cotton swabs, an evenly distributed bacterial lawn was prepared on Mueller-Hinton agar plates. Antimicrobial discs were placed on each bacterial lawn. The inhibition zone of each antimicrobial agent was analyzed after16-18 h of incubation at $37^{\circ} \mathrm{C}$. Results were interpreted according to the CLSI guidelines (CLSI, 2014). E. coli strain ATCC 29522 was used as a control strain in the susceptibility test. Multidrug resistance (MDR) was defined as resistance to at least one antimicrobial agent from three or more antimicrobial classes (Cantón and RuizGarbajosa, 2011).

\section{Results \\ Isolation and identification of Klebsiella sp.}

Klebsiella sp. like colonies on MacConkey agar with CTX were isolated from 30 out of 100 raw milk samples. The isolates were confirmed as Klebsiella sp. by biochemical tests. Among the upazillas, $40 \%, 33 \%, 20 \%$, and $7 \%$ Klebsiella sp.were isolated from raw milk of healthy cow in small holder dairy farm from MymensinghSadar, Muktagaccha, Fulpur, andTarakanda, respectively (Table 1).

Phenotypic screening for ESBL production Twenty $(66.7 \%)$ out of 30 Klebsiella sp.were identified to be ESBL-producer by phenotypic analysis (Table 1). Figure 1 showed ESBL production by Klebsiella sp. isolated from raw milk of healthy cow by double disk diffusion method. Among the upazillas, 50\%, 30\%, and $20 \%$ ESBL-Kleb were isolated from raw milk of healthy cow in small holder dairy farm from Mymensingh Sadar, Muktagaccha and Fulpur, respectively. However, no ESBL-Kleb was detected in raw milk from Tarakanda, (Table 1).

\section{Genotypic characterization of ESBL- producing Klebsiella sp.}

The 20ESBL-Kleb isolated from raw milk were subjected to ESBL genotyping viz. ${ }^{b l a} \mathrm{CTX}-\mathrm{M}$ $\left({ }^{b l a}\right.$ CTX-M-1, ${ }^{b l a}$ CTX-M-2), ${ }^{b l a}$ TEM and ${ }^{b l a}$ SHV. Analysis of ESBL genotype exhibited that ${ }^{b l a}$ TEM50\% (10/20) and ${ }^{b l a}$ SHV15\% (3/20) whereas combination of ${ }^{b l a}$ TEM with ${ }^{b l a} \mathrm{SHV}$ $35 \%(7 / 20)$ as shown in Table 2. However, neither ${ }^{b l a}$ CTX-M-1 nor ${ }^{b l a}$ CTX-M-2 was detected in this study. Figure 2 showed ESBL-encoding genes amplified from the multiplex PCR assay.

Determination of antimicrobial susceptibility

ESBL-Kleb isolates from raw milk were analyzed for their antimicrobial susceptibilities. As expected, all the tested ESBL-Kleb isolates showed resistance to AMP and CTX (Table 3). On the other hand, all the isolates were susceptible to CRO, IPM, CHL, FEP and AZM. The ESBL-Kleb isolates from raw milk were mainly resistant to GEN (100\%), CAZ (80\%), SMZ/TMP (40\%), OTC (30\%), STR (25\%), NAL $(15 \%)$, CIP, and FOX (10\%). MDR was observed in Klebsiella sp. carrying one ESBL group or their combination including ${ }^{b l a}$ TEM (40\%), ${ }^{b l a}$ TEM plus ${ }^{b l a} \mathrm{SHV}(43 \%)$ and ${ }^{b l a} \mathrm{SHV}(67 \%)$ as shown in Table 4. Notably, extensive MDR (XDR) bacteria, which is defined as resistance to at least five classes of antimicrobials, was detected in $14 \%$ of Klebsiella sp. carrying ${ }^{b l a}$ TEM and in $67 \%$ of Klebsiella sp. carrying ${ }^{b l a}$ SHV (Table 4). 
ESBL-producing Klebsiella sp. isolated from raw milk

Table 1. Detection of ESBL-producing Klebsiella sp. isolated from healthy cow raw milk

\begin{tabular}{lcccc}
\hline Name of the upazilas & $\begin{array}{c}\text { Dairy } \\
\text { farms } \\
\text { covered }\end{array}$ & $\begin{array}{c}\text { Sample } \\
\text { tested }\end{array}$ & $\begin{array}{c}\text { Klebsiella } \text { sp. } \\
\text { isolated }(\%)\end{array}$ & $\begin{array}{c}\text { ESBL-producing } \\
\text { Klebsiella } \text { sp. } \\
(\%)\end{array}$ \\
\hline MymensinghSadar & 27 & 30 & $12(40)$ & $10(50)$ \\
Muktagaccha & 25 & 30 & $10(33)$ & $6(30)$ \\
Fulpur & 19 & 20 & $6(20)$ & $4(20)$ \\
Tarakanda & 17 & 20 & $2(7)$ & $0(0)$ \\
\hline Total & 88 & 100 & 30 & $20(66.7)$ \\
\hline
\end{tabular}

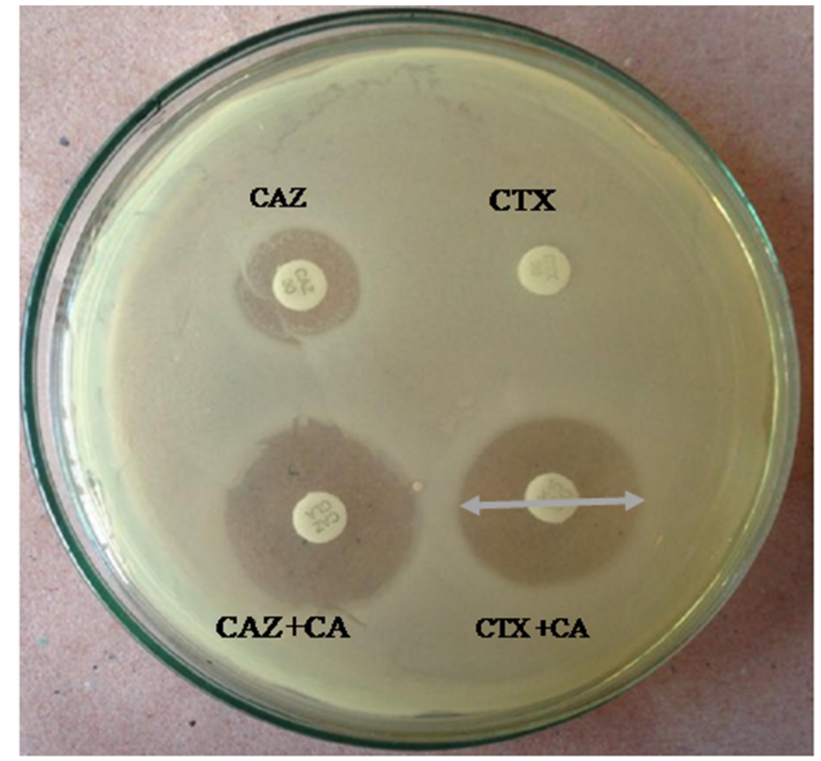

Figure 1. Detection of ESBL producing-Klebsiella sp. by double disk diffusion method results. The ESBLs producing-Klebsiella $\mathrm{sp}$. were considered as ESBL-producer when there was $5 \mathrm{~mm}$ or greater increase in the zone of inhibition (white arrow) with cefotaxime (CTX) /clavulanate (CA) or ceftazidime (CAZ)/CA in comparison to CTX or CAZ alone.

Table 2. ESBL pattern of ESBL-producing Klebsiella sp.isolated from healthy cow raw milk

\begin{tabular}{lc}
\hline ESBL group & No. of isolates (\%) \\
& $\mathrm{n}=20$ \\
\hline${ }^{b l a}$ TEM & $10(50)$ \\
${ }^{b l a}$ TEM, ${ }^{b l a}$ SHV & $7(35)$ \\
${ }^{b l a}$ SHV & $3(15)$ \\
\hline
\end{tabular}

n: total number of isolates. 
Nahar and others

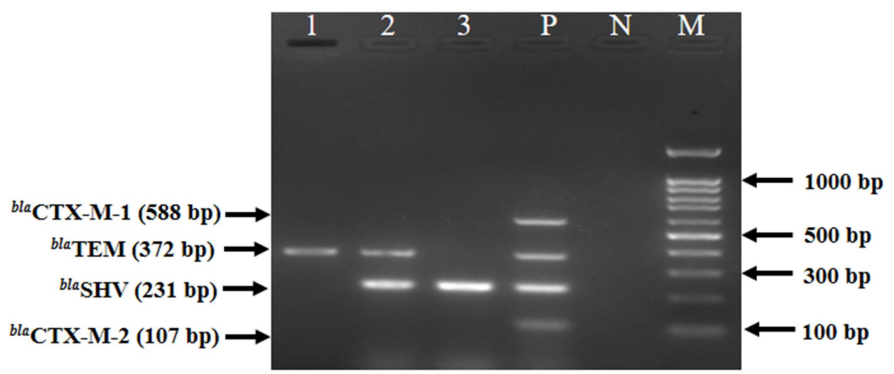

Figure 2. ESBL-encoding genes of Klebsiella sp.isolates from raw milk by multiplex PCR, followed by $1.5 \%$ agarose gel electrophoresis and ethidium bromide staining. Legends: $\mathrm{M}$ bla $=\mathrm{DNA}$ marker (100 bp), Lane $\mathrm{P}=$ Positive control, Lane $\mathrm{N}=$ Negative control, Lane 1 = Positive for TEM gene; Lane 2 $=$ Positive for SHV and TEM genes; Lane $3=$ Positive for SHV gene.

Table 3. Antimicrobial resistance of ESBL-producing Klebsiella sp.isolated from healthy cow raw milk

\begin{tabular}{lc}
\hline Antimicrobial agents & $\begin{array}{c}\text { No. of resistant isolates (\%) } \\
\mathrm{n}=20\end{array}$ \\
\hline AMP & $20(100)$ \\
CTX & $20(100)$ \\
CAZ & $16(80)$ \\
CRO & $0(0)$ \\
FOX & $2(10)$ \\
FEP & 0() \\
IPM & $0(0)$ \\
STR & $5(25)$ \\
GEN & $20(100)$ \\
CIP & $2(10)$ \\
NAL & $3(15)$ \\
OTC & $6(30)$ \\
CHL & $0(0)$ \\
AZM & $0(0)$ \\
SMZ/TMP & $8(40)$ \\
\hline
\end{tabular}

AMP: ampicillin, FOX: cefoxitin, CTX: cefotaxime, CAZ: ceftazidime, FEP: cefepime, CRO: ceftriaxone, IMP: imipenem, STR: streptomycin, GEN: gentamicin, CIP: ciprofloxacin, NAL: nalidixic acid, OTC: oxytetracycline, CHL: chloramphenicol, AZM: Azythromycine, SMZ/TMP: cotrimoxazoletrimethoprim. $\mathrm{n}$ : total number of isolates. 
Table 4. Multidrug resistance pattern in different ESBL group carrying Klebsiella $s p$. isolated from healthy cow raw milk

\begin{tabular}{|c|c|c|}
\hline ESBL group & MDR pattern ${ }^{\text {a }}$ (no. of isolate) & NARC $^{\mathbf{b}}$ \\
\hline \multirow[t]{5}{*}{${ }^{b l a}$ TEM $(\mathrm{n}=10)$} & SMZ/TMP, FOX, GEN, AMP, OTC (1) & 4 \\
\hline & SMZ/TMP, GEN, AMP (2) & 3 \\
\hline & FOX, GEN, AMP (1) & \\
\hline & STR, GEN, AMP (1) & 2 \\
\hline & GEN, AMP (5) & \\
\hline \multirow[t]{5}{*}{${ }^{b l a}$ TEM, ${ }^{b l a}$ SHV $(\mathrm{n}=7)$} & STR, NAL, SMZ/TMP, GEN, AMP, OTC (1) & 5 \\
\hline & STR, SMZ/TMP, GEN, AMP, OTC (1) & 4 \\
\hline & SMZ/TMP, GEN, AMP (1) & 3 \\
\hline & STR, GEN, AMP (1) & 2 \\
\hline & GEN, AMP (3) & \\
\hline \multirow[t]{3}{*}{${ }^{b l a} \mathrm{SHV}(\mathrm{n}=3)$} & STR, NAL, SMZ/TMP, GEN, AMP,CIP, OTC (1) & 6 \\
\hline & NAL, SMZ/TMP, GEN, AMP,CIP, OTC (1) & 5 \\
\hline & GEN, AMP (1) & 2 \\
\hline
\end{tabular}

aAMP: ampicillin, FOX: cefoxitin, CTX: cefotaxime, CAZ: ceftazidime,CIP: ciprofloxacin, GEN: gentamicin, STR: streptomycin, NAL: nalidixic acid, SMZ/TMP: cotrimoxazole-trimethoprim, OTC: oxytetracycline, ${ }^{\text {b }}$ o. of antimicrobial resistance classes according to CLSI (CLSI, 2012), n: total number of isolates.

\section{Discussion}

We performed a molecular surveillance to detect and characterize the ESBL-Kleb from raw milk of apparently healthy cow in small holder dairy farm in Mymensingh district, Bangladesh. About $30 \%$ of the total milk samples we screened were found to be Klebsiella sp. Positive. Similar finding was also reported from one study (Badri et al., 2017). One study in Bangladesh reported $62.5 \%$. Klebsiella sp. in mastitic milk (Salauddin et al., 2019). All positive Klebsiella sp. isolates showed typical cultural, morphological, and biochemical nature in this study which was also supported by Salauddin et al. (2019). AMR bacteria can transfer resistance genes horizontally to other bacteria and pose a risk to public health via the food chain. These AMR bacteria have been reported not only in food-animals but also in food-animal-derived products (meat, milk, and cheese) and thus may act as a potential source of resistant zoonotic bacteria (Yang et al., 2018; Yu et al., 2020; Watson et al., 2012). Therefore, food such as milk contaminated with ESBL-producing bacteria is thought to be one of the potential risk factors for the wide dissemination of ESBLproducing bacteria in humans (Lazarus et al., 2015). Our data showed that $67 \%$ of raw milk of healthy cow collected from small holder dairy farm of Mymensingh district, Bangladesh were positive for ESBL-Kleb. This finding is correlated with the findings of Badri et al. (2017) who reported $88.8 \%$ prevalence of ESBL-Kleb in raw milk of cow. In Bangladesh, Alipourfard and Nili (2010) reported $40 \%$ prevalence of ESBLKleb from hospital samples. Among the upazilas, there was a variation in the frequency of ESBKleb in raw milk of small holder dairy farm of Mymensingh Sadar, Muktagaccha, and Fulpur. However, we could not detect any ESBL-Kleb in raw milk from Tarakanda upazilla. This may be due to less number of Klebsiella sp. from raw milk of Tarakanda. Therefore, further study is 


\section{Nahar and others}

required to understand the real status of ESBLKlebraw milk of Tarakanda. In this study, we found that frequency of ESBL-Kleb in raw milk of healthy cow in the study area is relatively high which may be of important concern as these pathogens may be transferred to the human consumers as well as calves and thus might spread of AMR pathogens over human and animal population.

Furthermore, the analysis of beta-lactamase genes revealed that most of the isolates from raw milk carried ${ }^{b l a}$ TEM (50\%) than ${ }^{b l a}$ SHV (15\%). Badri et al. (2017) reported that Klebsiella sp.isolates from milk of cow with mastitis carried more ${ }^{b l a}$ SHV (23\%) than ${ }^{b l a}$ TEM (16\%). This variation may be due to difference in geographical position. Moreover, in this study, higher prevalence of ESBL-Kleb harboring the combination of ${ }^{b l a}$ TEM with ${ }^{b l a}$ SHV genes were also found, which indicates the potentiality of ESBL-Kleb to act as potential reservoir of ESBL genes.

It is well known that the plasmids bearing ESBL genes also can carry multiple resistant genes against aminoglycosides, chloramphenicol, sulfonamide, trimethoprim and tetracycline (Bonnet, 2004). In this study, ESBL-Kleb isolated from raw milk showed highest resistance to AMP, GEN followed by CAZ, SMZ/TMP, OTC, STR, NAL, CIP, and FOX. In India, resistant to TET, GEN, and AMP were also reported in ESBL-Kleb isolated from raw milk of dairy cattle in previous study (Badri et al., 2017). Gundogan and Avci (2013) also showed resistant to CAZ, TET and CIP in ESBL-Kleb isolated from foods of animal origin. It is known that GEN, TET, sulphonamide are often used in dairy farm as therapeutics and prophylaxis in Bangladesh. Thus, indiscriminate or excessive use of these drugs might have contributed to resistance against these antimicrobials. In this study, all isolates showed $100 \%$ sensitivity to IPM, FEP was also observed by others (Uddin et al., 2011; Tekiner et al., 2016). In this study, high rate of MDR was observed in different groups of ESBL carrying Klebsiella sp. isolated from raw milk. This finding may be relevant as MDR has been observed in Klebsiella sp. isolated from milk in a previous study in Bangladesh (Uddin et al., 2010). Most importantly, XDR was also found in high number of ESBL-Kleb isolated from raw milk in this study indicating potentiality of these isolates as reservoir of AMR and might be harmful for public health. So far we know, this is the first study which detected the ESBL-Kleb from raw milk of healthy cow of small holder dairy farm in Bangladesh.

\section{Conclusions}

More than $66 \%$ of the Klebsiella sp. strains isolated from raw milk of healthy cattle carried ESBL genes. Raw milk might as potential carrier of ESBL-Kleb which may have detrimental impacts on public health. Moreover, these ESBLKlebs were highly MDR and XDR which can easily be transmitted between closely related pathogens and thus result in potential health hazards due to failure of treatment with common antimicrobials available in markets. Therefore, proper monitoring of food producing animal's derived products should be undertaken to combat these dreadful pathogens.

\section{Funding}

This research was funded by Ministry of Education, Government of People's Republic of Bangladesh [grant number LS-14196]. This study was also partly funded by the Ministry of Education, Government of People's Republic of Bangladesh [grant number LS-14196].

\section{Ethics Statement}

Ethical review and approval was not required for the animal study because no ethical review and approval required for this study where animal subjects were only submitted to milk from teat. Written informed consent was obtained from the owners for the participation of their animals in this study.

\section{Acknowledgements}

The authors are grateful to small holder dairy farmers for providing the milk samples. We would also like to acknowledge Professor Dr. Shinji Yamasaki, Graduate School 
of Life and Environmental Sciences, Osaka Prefecture University, Osaka 598-8531, Japan for providing the positive control of the ESBL genes in the current study.

\section{Conflict of Interests}

The authors declare that there is no conflict of interests regarding the publication of this paper.

\section{References}

1. Alipourfard I, Nili NY. Antibiogram of Extended Spectrum Beta-lactamase (ESBL) producing Escherichia coli and Klebsiella pneumoniae isolated from Hospital Samples. Bangladesh Journal Medical Microbiology. 2010; 04 (01): 32-36.

2. Badri AM, Ibrahim IT, Mohamed SG, Garbi MI, Kabbashi AS, Arbab MH. Prevalence of extended-spectrum beta-lactamase (ESBL) producing Escherichia coli and Klebsiella pneumonia isolated from raw milk samples in Al Jazirah State, Sudan. Molecular Biology. 2017;7: 201.

3. Bonnet, R. Growing group of extendedspectrum $\beta$-lactamases: the CTX-M enzymes. Antimicrobial Agents Chemotherapy. 2004; 48: 1-14.

4. Cabral AB, MeloRde C, Maciel MA, Lopes AC. Multidrug resistance genes, including ${ }^{b l a} \mathrm{KPC}$ and ${ }^{b l a} \mathrm{CTX}-\mathrm{M}-2$, among Klebsiella pneumoniae isolated in Recife, Revista da Sociedade Brasileira de Medicina Tropical. 2012; 45(5):572-8.

5. Cantón R, Ruiz-Garbajosa P. Co-resistance: an opportunity for the bacteria and resistance genes. Current Opinion in Pharmacology. 2011; 11: 477-485.

6. CLSI. Methods for dilution antimicrobial susceptibility tests for bacteria that grow aerobically; Approved standard-ninth edition M7-A9. Wayne, PA, USA. 2012.

7. CLSI. Performance standards for antimicrobial susceptibility testing. TwentyFourth Informational (Supplement): M100S24 Wayne, PA, U.S.A. 2014.

8. Gundogan N, Avci E. Prevalence and antibiotic resistance of extended spectrum beta-lactamase (ESBL) producing
Escherichia coli and Klebsiella sp.ecies isolated from foods of animal origin in Turkey. African Journal of Microbiology Research. 2013; 7(31):4059-4064.

9. Guo Y, Wang S, Zhan L, Jin Y, Duan J, Hao Z, Lv J, Qi X, Chen L, Kreiswirth BN, Wang $\mathrm{L}, \mathrm{Yu} \mathrm{F}$. Microbiological and clinical characteristics of hypermucoviscous Klebsiella pneumoniae isolates associated with invasive infections in China. Frontiers in Cellular and Infection Microbiology. 2017; $7: 24$.

10. Hickey CD, Sheehan JJ, Wilkinson MG, Auty MAE. Growth and location of bacterial colonies within dairy foods using microscopy techniques: A review. Frontiers in Microbiology. 2015; 6: 99.

11. Lautenbach E, Patel JB, Bilker WB, Edelstein PH, Fishman NO. Extendedspectrum beta-lactamase-producing Escherichia coli and Klebsiella pneumoniae: risk factors for infection and impact of resistance on outcomes. Clinical Infectious Diseases. 2001; 32(8):1162-71.

12. Lazarus B, Paterson DL, Mollinger JL, Rogers BA. Do human extraintestinal Escherichia coli infections resistant to expanded spectrum cephalosporins originate from food-producing animals? A systematic review. Clinical Infectious Diseases. 2015; 60: 439-452.

13. Nahar A, Awasthi SP, Hatanaka N, Okuno K, Hoang PH, Hassan J, Hinenoya A, Yamasaki S. Prevalence and characteristics of extended-spectrum $\beta$-lactamase-producing Escherichia coli in domestic and imported chicken meats in Japan. Journal of Veterinary Medical Science.2018; 80: 510-517.

14. Naseer U, Sundsfjord A. The CTX-M conundrum: dissemination of plasmids and Escherichia coli clones. Microbial Drug Resistance. 2011; 17: 83-97.

15. Oliver SP, Jayarao BM and Almeida RA. Foodborne pathogens in milk and the dairy farm environment: Food safety and public health implications. Foodborne Pathogens and Disease. 2005; 2: 115-129. 


\section{Nahar and others}

16. Ombarak RA, Hinenoya A, Awasthi SP, Iguchi A, Shima A, Elbagory ARM, Yamasaki S. Prevalence and pathogenic potential of Escherichia coli isolates from raw milk and raw milk cheese in Egypt. International journal of food microbiology. 2016; 221: 69-76.

17. Parvin MS, Talukder S, Ali MY, Chowdhury EH, Rahman MT, Islam MT. Antimicrobial resistance pattern of Escherichia coli isolated from frozen chicken meat in Bangladesh. Pathogens. 2020; 9: 420.

18. Phuc Nguyen MC, Woerther PL, Bouvet M, Andremont, A, Leclercq R, Canu A. Escherichia coli as reservoir for macrolide re sistance genes.Emerging Infectious Diseases. 2009; 15: 1648-50.

19. Rahman MA, Rahman AKMA, Islam MA, Alam MM. Antimicrobial resistance of Escherichia coli isolated from milk, beef and chicken meat in Bangladesh. Bangladesh Journal of Veterinary Medicine. 2017; 15: 141-146.

20. Salauddin M, Akter MR, Hossain MK, Rahman MM. Isolation of multi-drug resistant Klebsiella sp. from bovine mastitis samples in Rangpur, Bangladesh.Journal of Advanced Veterinary and Animal Research. 2019; 6(3):362-365.

21. Tekiner $\dot{\mathrm{IH}}$, Özpınar H. Occurrence and characteristics of extended spectrum betalactamases-producing Enterobacteriaceae from foods of animal origin. Brazilian Journal of Microbiology.2016; 47(2):444-51.

22. Tenover FC, Mohammed MJ, Gorton TS, Dembek ZF. Detection and reporting of organisms producing extended spectrumbeta-lactamases: Survey of laboratories in Connecticut. Journal of Clinical Microbiology. 1999; 37: 4065-4070.

23. Uddin MA, Motazzim-ul-Haque HM, Noor R. Isolation and Identification of Pathogenic Escherichia coli, Klebsiella sp. and Staphylococcus spp. in Raw Milk Samples Collected from Different Areas of Dhaka City, Bangladesh. Stamford Journal of Microbiology. 2011; 1(1): 19-23.

24. Watson E, Jeckel S, Snow L, Stubbs R, Teale $\mathrm{C}$, Wearing H, ColdhamN. Epidemiology of extended spectrum beta-lactamase $E$. coli (CTX-M-15) on a commercial dairy farm. Veterinary Microbiology. 2012; 154:339-346.

25. Woerther PL, Burdet C, Chachaty E, Andremont A. Trends in human fecal carriage of extended-spectrum $\beta$-lactamases in the community: toward the globalization of CTX-M. Clinical Microbiology Reviews. 2013; 26: 744-758.

26. Yang F, Zhang SD, Shang XF, Wang XR, Wang L, Yan ZT, Li HS. Prevalence and characteristics of extended spectrum $\beta$ lactamase-producing Escherichia coli from bovine mastitis cases in China. Journal of Integrative Agriculture.2018; 17: 1246-1251.

27. Yu Y, Zhou ZQ. Detection of food-borne diseases caused by Klebsiella pneumoniae. Zhe Jiang Prevent Medicine.2013.25:93-94.

28. Yu ZN, Wang J, Ho H, Wang YT, Huang SN, Han RW. Prevalence and antimicrobialresistance phenotypes and genotypes of Escherichia coli isolated from raw milk samples from mastitis cases in four regions of China. Journal of Global Antimicrobial Resistance. 2020; 22: 94-101.

29. Zając M, Sztromwasser P, Bortolaia V, Leekitcharoenphon P, Cavaco LM, ZiętekBarszcz A, Hendriksen RS, Wasyl D. Occurrence and characterization of mcr-1positive Escherichia coli isolated from foodproducing animals in Poland, 2011-2016. Frontiers in Microbiology. 2019; 10:2816.

30. Zhou X, Gao J, Huang Y, Fu S, Chen H. Antibiotic resistance pattern of Klebsiella pneumonia and Enterobacter sakazakii isolates from powdered infant formula. African Journal of Microbiology Research.2011;5: 3073-3077. 